\title{
Pemikiran Wahid Hasyim tentang Pendidikan dan Relevansianya dengan Dunia Modern
}

\author{
Nurhabibah \\ Program Magister Konsentrasi Pendidikan Agama Islam \\ Fakultas Ilmu Tarbiyah dan Keguruan Universitas Islam Negeri Sunan Kalijaga Yogyakarta \\ Jalan Laksda Adisucipto, Caturtunggal, Depok, Papringan, Caturtunggal, Kec. Depok, \\ Kabupaten Sleman, Daerah Istimewa Yogyakarta 55281 \\ e-mail: habibahnoenk1@gmail.com
}

\begin{abstract}
$\mathrm{KH}$ Wahid Hasyim is a figure of clergy and statesman who is undoubtedly his service to the state. As a cleric, he is son of KH Hasyim Asy'ari, the founder of Nahdatul Ulama, the largest Islamic organization in Indonesa. As a statesman, he served as a minister of religion. His work in the academic world and his struggle and educating the people is well known and made an impression. In outlining the policy in the world of education, certainly not apart from the Islamic backround and statesmanship he has. This make his thinking to be balanced between the inner and outer dimensions, between traditionality and modernity. This paper attemps to decipher Wahid Hasyim's biography and the examines his thoughts in education as well as his relation to education in the modern world. The significance of this paper is as a literature for the biography of Wahid Hasyim and the relevance of his thought to education from time to time.
\end{abstract} Keyword: Wahid Hasyim, education, modern

\begin{abstract}
Abstrak
KH Wahid Hasyim adalah sosok agamawan dan negarawan yang tidak diragukan jasanya bagi negara. Sebagai agamawan, dia adalah putera KH Hasyim Asyari, pendiri Nahdlatul Ulama yang merupakan organisasi Islam terbesar. Sebagai negarawan, dia pernah menjabat sebagai menteri agama. Kiprahnya di dunia akademik dan perjuangannya dalam mendidik bangsa sangat dikenal dan berbekas. Dalam menggariskan kebijakan di dunia pendidikan, tentu tidak terlepas dari latar belakang keislaman dan kenegarawanan yang dia sandang. Hal ini membuat pemikirannya menjadi seimbang antara dimensi lahir dan batin. Tulisan ini mencoba menguraikan biografi Wahid Hasyim lalu menelaah pemikirannya di bidang pendidikan sekaligus kaitannya dengan pendidikan di dunia modern. Signifikansi dari tulisan ini adalah sebagai literatur untuk mengetahui biografi Wahid Hasyim serta relevansi pemikirannya dengan pendidikan dari masa ke masa.
\end{abstract}

Kata Kunci: Wahid Hasyim, pendidikan, modern

\section{PENDAHULUAN}

Salah satu peran ulama yang patut diketahui adalah posisinya sebagai kelompok terpelajar yang membawa pencerahan kepada masyarakat sekitarnya. Berbagai lembaga pendidikan telah di lahirkan oleh mereka baik dalam bentuk sekolah maupun pondok pesantren. Semua itu adalah lembaga yang ikut mengantarkan bangsa Indonesia menjadi bangsa yang maju dan berpendidikan. Mereka telah berperan dalam memajukan ilmu pengetahuan, khususnya pendidikan Islam lewat karya-karya yang telah ditulis atau melalui jalur dakwah. 
Wahid Hasyim adalah salah satu pahlawan yang lahir dari rahim pesantren, ia telah menorehkan jasa besar bagi kemajuan pendidikan Islam Indonesia. Gagasan-gagasan yang cemerlang muncul sebagai kepedulian Wahid Hasyim terhadap kemajuan umat Islam Indonesia. Hal ini sangat menarik untuk dikaji karena dia adalah sosok tangguh yang pantang menyerah dalam perjuangan memajukan bangsa. Dalam tulisan ini akan dikaji bagaimana pemikiran pendidikan Wahid Hasyim dan relevansinya dengan pendidikan di masa modern.

Wahid Hasyim adalah anak kelima dari pasangan KH Hasyim Asy'ari dan Nyai Nafiqah, Ia merupakan anak laki-laki pertama dari 10 bersaudara, dilahirkan pada hari Jum'at 1 juni 1914 di Tebuireng, Jombang. Nama asli beliau adalah Abdul Wahid, tapi ketika menginjak dewasa Ia lebih suka menulis namanya dengan $\mathrm{A}$. Wahid dan ditambah nama ayahnya dibelakangnya, sehingga menjadi A. Wahid Hasyim. ${ }^{1}$

Sebagai anak seorang kyai terkenal, Wahid Hasyim tumbuh dan berkembang dalam lingkungan pesantren yang sarat dengan nilainilai keagamaan. Pendidikan dasarnya dilalui di lingkungan rumahnya. Saat itu ada sekolah modern yang diperkenalkan oleh kolonial, tetapi mereka yang mendapat kesempatan belajar di lembaga pendidikan modern tersebut masih sangat terbatas. Selain itu, jenis pendidikan tersebut, ketika Wahid Hasyim kecil, belum menyentuh pesantren. Tidak aneh bila dia tidak pernah duduk dibangku sekolah umum dan hanya belajar di madrasah yang ada di lingkungan pesantren orang tuanya pada pagi hari, ditambah malam hari belajar langsung dengah ayahnya. ${ }^{2}$ Pada umur 13 tahun, ia pergi ke Pondok Siwalan Panji, Sidoarjo. Di sana ia mempelajari kitab-kitab Bidayah, Sulamut Taufiq, Taqrib dan Tafsir Jalalain. Akan tetapi sayang, Ia belajar di Panji tidak lama, hanya

${ }^{1}$ Menteri-menteri Agama RI, Biografi Sosial Politik, (Jakarta: Badan Litbang Agama, Departemen Agama RI ,1998), hlm.100

${ }^{2}$ Ibid., hlm. 100
25 hari. Pada tahun berikutnya ia mondok di Lirboyo, Kediri, akan tetapi mondok yang kedua kali ini pun hanya untuk beberapa hari belaka. ${ }^{3}$ Di usia 18 tahun Wahid Hasyim melaksanakan ibadah haji sekaligus memperdalam ilmu pengetahuan di Mekah. ${ }^{4}$

Wahid Hasyim menguasai bahasa Belanda, Inggris dan Jerman sejak usia dini, karena beruntung memiliki saudara sepupu Muhammad Ilyas yang sejak 1918 mengikuti pendidikan di "Hollands Inlandsche Scule (HIS)" antara tahun 1918-1926. ${ }^{5}$ HIS merupakan sekolah dengan status tertinggi. Sekolah yang mempunyai kurikulum 7 tahun ini khusus bagi murid-murid Indonesia yang berasal dari kalangan terkemuka baik segi jabatan maupun keturunan. ${ }^{6}$

Kyai Wahid Hasyim adalah seorang tokoh pendidikan sekaligus seorang ulama yang pernah menjabat sebagai mentri agama pertama di Indonesia. Beliau memiliki pengaruh besar terhadap perkembangan pendidikan di Indonesia terutama pendidikan agama islam, pemikiran-pemikiran beliau tentang pendidikan agama islam akan dibahas lebih luas pada bab selanjutnya.

\section{Analisis}

Membahas pemikiran pendidikan yang digagas oleh Wahid Hasyim dirasa sangat menarik. Oleh karena itu dalam pembahasan ini penulis merumuskan konsep yang digagas oleh Wahid Hasyim menjadi tiga aspek, yaitu:

\section{Tujuan Pendidikan}

Pendidikan menurut Wahid Hasyim bertujuan untuk menggiatkan santri yang berakhlakul karimah, takwa kepada Allah serta

${ }^{3}$ Abu Bakar, Sejarah hidup KH.A Wahid Hasyim, (Bandung: Mizan, 2011), hlm. 162

${ }^{4}$ Ahmad Danuji, "Pemikiran Wahid Hasyim Tentang Islam dan Kewargaan", Skripsi, Fakultas Syari'ah an Hukum, Unversitas Islam Negeri Sunan Kalijaga Yogyakarta, 2014, hlm. 41

${ }^{5}$ Shofiyullah, KH Wahid Hasyim: Sejarah, Pemikiran, dan Baktinya bagi Agama dan Bangsa, (Jombang: Pesantren Tebuireng, 2011), hlm. 316

${ }^{6}$ Arel A. Steenbrink, Pesantren Madrasah Sekolah, ( Jakarta: LP3ES, 1986 ), hlm.24 
memiliki keterampilan untuk hidup. Model lama tarbiyah Islam yang terjebak pada pendekatan teosentris juga beliau setting ulang dengan nuansa antroposentris sebagai upaya untuk membumikan ajaran Islam yang lebih realistis, faktual dan update. Dengan penekanan ini Kyai Wahid berharap agar nantinya para alumni mampu menjawab persoalan masyarakat.

Artinya, pendidikan itu harus memenuhi tuntutan duniawi dan ukhrowi, moralitas dan akhlak. Titik tekannya adalah pada kemampuan kognisi (iman), afeksi (ilmu), juga psikomotor (amal, akhlak yang mulia). Selain itu, beliau juga menekankan pendidikan yang memosisikan akal (logika dalam istilah Wahid Hasyim) dan agama secara seimbang dan proporsional.

Adapun tujuan-tujuan dari pemikiran Kyai Wahid adalah paradigma pendidikan Islam inklusif. Sikap inklusif ini sebaiknya dimiliki oleh civitas akademika pelaku pendidikan Islam di Indonesia. Reformasi radikal yang dilakukan oleh Kyai Wahid terhadap model pendidikan Islam yang dikenal konservatif tidak lain adalah bagian dari usaha membentuk model pendidikan Islam yang adaptif terhadap isuisu aktual, hal ini dilakukan untuk mendobrak mainstream tentang kekolotan pesantren yang hanya bergumul dengan kitab-kitab klasik. ${ }^{7}$

\section{Kurikulum Pendidikan Islam}

Kurikulum ialah suatu program rancangan pendidikan yang isinya sejumlah mata pelajaran dan program kegiatan yang diperlukan sebagai syarat untuk syarat untuk menyelesaikan suatu program pendidikan. ${ }^{8}$

Pandangan para Kyai dan masyarakat pesantren pada waktu itu hanya menghususkan pengajaran "agama" saja dan mengharamkan pengajaran pengetahuan umum, bahasabahasa asing, huruf latin, dan matematika. Bahkan menggunakan bangku dan papan tulis juga dianggap tidak sesuai dengan kehidupan beragama. ${ }^{9}$

\footnotetext{
${ }^{7}$ Shofiyullah, KH Wahid Hasyim..,hlm. 361-362

${ }^{8}$ Maragustam Siregar, Filsafat Pendidikan Islam, (Yogyakarta: Kurnia Alam Semesta: 2016), hlm.236 ${ }^{9}$ Shofiyullah, KH Wahid Hasyim..,hlm. 324
}

Keterbukaan Wahid Hasyim terhadap segala hal baru dan pemikirannya yang cukup maju dapat dilihat ketika ia mengusulkan perubahan kurikulum di pondok pesantren. Ide yang ditawarkan adalah memasukkan ilmu pengetahuan sekuler dalam kurikulum pesantren. Hal ini dimaksudkan agar santri tidak hanya menguasai ilmu agama, tetapi juga menguasai ilmu-ilmu pengetahuan modern. Dengan dikuasainya kedua ilmu tersebut, santri dalam pandangan Wahid Hasyim, akan menjadi manusia sempurna. ${ }^{10}$

Wahid Hasyim mencoba mengoreksi harapan santri belajar di pesantren. ia mengusulkan agar santri dating ke pesantren tidak perlu menghabiskan waktu semuanya berharap menjadi ulama. Oleh karena itu, merekatidak perlu menghabiskan waktu bertahun-tahun dalam mengakumulasi ilmu agma melalui teks-teks Arab. Mereka dapat memperoleh ilmu agama dari buku-buku yang ditulis dengan huruf latin,dan menghabiskan sisa waktunya untuk mempelajari berbagai ilmu pengetahuan dibarengi kemampuan menguasai keterampilan yang berguna secara langsung di tengah masyarakat dimana mereka berada. Hanya sebagian kecil saja yang disiapkan menjadi ulama yang diajari bahasa Arab dan karya-karya klasik dari abad pertengahan. Hasyim Asyari tidak setuju dengan dua usulan tersebut karena dianggap terlalu radikal dan sangat bertolak belakang dengan pemikiran pemimpin pesantren saat itu. Akan tetapi, Hasyim Asyari mengizinkan putranya untuk mendirikan institusi pada 1935. Institusi tersebut dapat dikategorikan sebagai reformasi pendidikan yang paling monumental di dunia pesantren pada waktu itu. ${ }^{11}$

Wahid Hasyim mendirikan Madrasah Nizamiyah, berbeda dengan sistem tradisional yang masih terus berjalan di pesantren, institusi baru yang yang digagas Wahid Hasyim menggunakan ruang kelas dengan kurikulum $70 \%$ pelajaran umum dan $30 \%$ pelajaran agama.

\footnotetext{
${ }^{10}$ Ibid.,hlm.341

${ }^{11}$ Ibid.,hlm. 344-345
} 
Pelajaran sekuler yang diajarkan di Madrasah Nizamiyah adalah aritmatika, sejarah, geografi dan ilmu pengetahuan alam. Sebagai tambahan, santri diajari pelajaran bahasa, yakni bahasa Indonesia, Inggris dan Belanda. Keterampilan mengetik juga diberikan untuk meningkatkan kualitas keterampilan santri. ${ }^{12}$

Langkah ini merupakan inovasi baru bagi kalangan pesantren, pada saat itu pelajaran umum masih dianggap hal tabu oleh pesantren karena dipandang identik dengan bangsa barat. Kebencian mendalam terhadap penjajah membuat pesantren mengharamkan semua yang berkaitan dengannya, seperti memakai dasi dan topi. ${ }^{13}$

Berkaitan dengan peningkatan kebiasaan membaca dan kualitas pengetahuan siswa, Wahid Hasyim mendirikan sebuah perpustakaan. Buku yang tersedia kurang lebih 1000 judul buku, yang terdiri dari buku-buku teks dan karyakarya ilmiah popular baik yang ditulis dalam bahasa Arab, Inggris, Belanda Indonesia dan Jawa. ${ }^{14}$

Pembaharuan pendidikan yang digagas Wahid Hasyim tidak luput dari kritik tajam ulama dan masyarakat. Ide pembaharuan Wahid Hasyim sering menjadi sasaran kritik yang dilontarkan ulama sebagai upaya mencampuradukan ajaran agama yang suci dengan ilmu-ilmu keduniawian, yang mana ilmu-ilmu sekuler tersebut masih dianggap sebagai produk bangsa kolonial. Pada akhirnya, walaupun memakan waktu yang lama, Wahid Hasyim mampu meyakinkan mereka akan manfaat yang dapat diperoleh dengan ide pembaharuannya tersebut. setiap ada kesempatan, Ia selalu menggunaknnya untuk menjelaskan tujuan dan kegunaan dari ide pembaharuannya. Sebagai bukti, Ia menunjukkan hasil positif dari sIstem baru tersebut, yaitu dengan memperlihatkan kemampuan yang dimiliki para siswa yang belajar di Madrasah Nizamiyah, termasuk penguasaan ilmu agama dan sekaligus

\footnotetext{
${ }^{12}$ Ibid.,hlm. 345

${ }^{13}$ Menteri-menteri Agama RI, Biografi..,hlm.102

${ }^{14}$ Shofiyullah, KH Wahid Hasyim...,hlm.345
}

kemampuan berbahasa asing. Melalui upaya penyadaran tersebut, Kyai dan masyarakat secara perlahan dapan memahami dan menerima gagasan Wahid Hasyim. ${ }^{15}$

\section{Metode Pembelajaran}

Metode ialah seperangkat cara, jalan dan teknik yang digunakan oleh pendidik dalam proses pembelajaran untukmencapai tujuan pendidikan yang telah dirumuskan atau menguasai kompetensi menuju terwujudnya kepribadian Muslim ${ }^{16}$. Lalu sekembalinya dari Mekkah Wahid Hasyim mengusulkan kepada ayahnya suatu perubahan radikal dalam sistem pengajaran di pesantren, yaitu sistem bandongan diganti dengan sistem tutorial yang sistematis dengan tujuan untuk mengembangkan inisiatif dan kepribadian para santri. Ini berarti pengajaran di pesantren tidak terbatas hanya pengajian kitab-kitab Islam klasik, melainkan para santri diajarkan lebih banyak lagi mata pelajaran umum. ${ }^{17}$

Pada mulanya ada dua metode yang digunakan dalam proses pembelajaran di pesantren. Pertama, metode bandongan, yaitu; metode ini dilakukan seorang kiyai atau ustadz terhadap sekelompok santri untuk mendengarkan atau menyimak apa yang dibacakan oleh Kyai dari sebuah kitab. Santri dengan memegang kitab yang sama, masingmasing melakukan penulisan harakat dan membuat catatan padanya. ${ }^{18} \mathrm{Kedua}$, metode sorogan(menyodorkan) yaitu, seorang santri yang mendapat giliran menghadap langsung secara tatap muka kepada kyai atau ustadz, kemudian ia membuka bagian yang akan dibaca atau dikaji bersama kyai atau ustadz. ${ }^{19}$

\footnotetext{
${ }^{15}$ Ibid.,hlm.348

${ }^{16}$ Maragustam Siregar, Filsafat ..,hlm. 223

${ }^{17}$ Zamakshari Dhofir, Tradisi Pesantren: Studi
} Tentang Pandangan Hidup Kyai, (Jakarta: LP3ES, 1994), hlm. 105

${ }^{18}$ Departemen Agama RI, Direktorat Jenderal Kelembagaan Agama Islam, Pondok Pesantren dan Madrasah Diniyah Pertumbuhan dan Perkembangannya, (Jakarta: Departemen Agama RI, 2003), hlm. 40 ${ }^{19}$ Ibid.,hlm. 38 
Mengenai keefektifan metode yang digunakan di pesantren, Wahid Hasyim mengusulkan untuk mengadopsi sistem tutorial, sebagai ganti dari metode bandongan. Menurutnya, metode bandongan tidak efektif dalam mengembangkan inisiatif santri. Hal ini disebabkan dikelas dimana metode ini diterapkan, santri hanya datang untuk mendengar, menulis dan menghafal pelajaran yang diberikan, tidak ada kesempatan bagi santri untuk mengajukan pertanyaan atau bahkan mendiskusikan pelajaran. Wahid Hasyim menyimpulkan bahwa metode bandongan membuat santri pasif. ${ }^{20}$

\section{Diskusi}

Pendidikan menurut Wahid Hasyim bertujuan untuk menggiatkan santri yang berakhlakul karimah, takwa kepada Allah serta memiliki keterampilan untuk hidup.Upaya serta pemikiran beliau tersebut relevan dengan tujuan pendidikan nasional, yang termuat dalam sistem pendidikan Undang-Undang No. 20 tahun 2003 bab 2 pasal 3, yang berbunyi: mengembangkan kemampuan dan membentuk watak serta peradaban bangsa yang bermartabat dalam rangka mencerdaskan kehidupan bangsa, bertujuan untuk berkembangnya potensi peserta didik agar menjadi manusia yang beriman dan bertaqwa kepada Tuhan Yang Maha Esa, berakhlak mulia, sehat, berilmu, cakap, kreatif, mandiri, dan menjadi warga Negara yang demokratis serta bertanggung jawab. ${ }^{21}$

Begitu juga dengan kurikulum pendidikan yang di usung oleh beliau sangat relevan dengan kurikulum modern, yakni dengan menjembatani ilmu umum dengan ilmu agama, sebab kemajuan dunia modern tidak hanya membutuhkan pendidikan agama saja akan tetapi juga mebutuhkan pendidikan umum agar masyarakat Indonesia mampu menghadapi persoalan hidup di dunia modern.

Selain itu, perubahan metode belajar dari metode bandongan dan sorogan yang di nilai

\footnotetext{
${ }^{20}$ Shofiyullah, KH Wahid Hasyim..,hlm. 344

${ }^{21}$ Undang-Undang SISDIKNAS (Jakarta: Sistem Pendidikan Nasional,2003), hlm.6
}

akan mengakibatkan santri atau siswa menjadi pasif diubah menjadi metode tutorial yang bersifat membantu dan membimbing, sehingga santri atau murid dapat belajar aktif. Metode belajar ini memiliki relevansi dengan metode belajar di era modern seperti halnya metode belajar PAIKEM, yakni Pembelajaran Aktif, Inofatif, Kreatif, Efektif dan Menyenangkan.

\section{KESIMPULAN}

Wahid Hasyim adalah anak kelima dari pasangan KH Hasyim Asy'ari dan Nyai Nafiqah, ia merupakan anak laki-laki pertama dari 10 bersaudara, dilahirkan pada hari jum'at 1 juni 1914 di Tebuireng, Jombang. Sebagai anak seorang kyai terkenal, Wahid Hasyim tumbuh dan berkembang dalam lingkungan pesantren yang sarat dengan nilai-nilai keagamaan. Pendidikan dasarnya dilalui dilingkungan rumahnya, saat pagi belajar di madrasah dan malamnya belajar pada Ayahnya. Kyai Wahid Menjabat sebagai menteri agama pertama pada tahun 1949.

Pemikiran pendidikan Wahid Hasyim tertuang dalam tiga aspek, yaitu: Pertama menyatakan tujuan pendidikan Islam adalahmenggiatkan santri yang berakhlakul karimah, takwa kepada Allah serta memiliki keterampilan untuk hidup. Kedua, memasukan pelajaran-pelajaran umum sebagai penambahan kurikulum dilingkungan pesantren. Ketiga, menambah metode tutorial sebagai pengganti metode bandongan yang dirasa kurang efektif dalam melatih keaktifan santri.

Pemikiran Wahid Hasyim dirasa masih relevan dengan pendidikan di era modern, baik dilihat dari tujuan pendidikan, kurikulum dan metode pendidikan.

\section{DAFTAR PUSTAKA}

Steenbrink, K., Pesantren Madrasah Sekolah. (Jakarta: LP3ES, 1986)

Departemen Agama RI, Direktorat Jenderal Kelembagaan Agama Islam, Pondok Pesantren dan Madrasah Diniyah Pertumbuhan dan Perkembangannya. (Jakarta: Departemen Agama RI. 2003) 
Undang-undang dan Peraturan Pemerintah RI tentang Pendidikan. (Jakarta: Direktorat Jenderal Pendidikan Islam Departemen Agama RI, 2006)

Badan Litbang Agama, Menteri-menteri Agama RI: Biografi Sosial Politik, (Jakarta: Badan Litbang Agama Departemen Agama RI, 1998)

Shofiyullah, KH Wahid Hasyim: Sejarah, Pemikiran, dan Baktinya bagi Agama dan Bangsa, (Jombang: Pesantren Tebuireng, 2011)
Siregar, M., Filsafat Pendidikan Islam, (Yogyakarta: Kurnia Alam Semesta, 2016)

Danuji, A., Pemikiran Wahid Hasyim Tentang Islam dan Kewargaan, Skripsi, Fakultas Syari'ah an Hukum, Unversitas Islam Negeri Sunan Kalijaga Yogyakarta, 2014 Dhofir, Z., Tradisi Pesantren: Studi Tentang Pandangan Hidup Kyai, (Jakarta: LP3ES, 1994) 